\title{
Miniaturized Wideband Aperture Coupled Microstrip Patch Antenna by Using Inverted U-Slot
}

\author{
Amandeep Singh ${ }^{1}$ and Surinder Singh ${ }^{2}$ \\ ${ }^{1}$ Department of ECE, CT Institute of Engineering Management \& Technology, Jalandhar, India \\ ${ }^{2}$ Department of ECE, Sant Longowal Institute of Engineering and Technology, Longowal 148106, India \\ Correspondence should be addressed to Surinder Singh; surinder_sodhi@rediffmail.com
}

Received 13 October 2013; Revised 3 February 2014; Accepted 12 February 2014; Published 4 May 2014

Academic Editor: Shaoqiu Xiao

Copyright (c) 2014 A. Singh and S. Singh. This is an open access article distributed under the Creative Commons Attribution License, which permits unrestricted use, distribution, and reproduction in any medium, provided the original work is properly cited.

\begin{abstract}
This paper presents a linear polarized aperture coupled inverted U-slot patch antenna with small steps at the edges. The proposed design exhibits wideband behavior, acceptable return loss, VSWR, gain, small size, and less complexity. The theoretical analysis is based on the finite element method (FEM). This design has wide bandwidth, good return loss, VSWR, and radiation characteristics by implanting the inverted U-shaped stepped slots on a single aperture coupled patch. The proposed antenna design shows the measured return loss within acceptable range throughout the band $(11.08 \mathrm{GHz}-13.25 \mathrm{GHz})$ and maximum return loss is achieved with proper impedance matching. In this paper, the design considerations are presented and results are validated by the calculated and measured parameters.
\end{abstract}

\section{Introduction}

The microstrip patch antenna has been popularized because it is being utilized in many modern communication systems for its tremendous characteristics such as light weight, small size, low cost and easy fabrication [1,2]. Pozar [3] has proposed the aperture coupled microstrip antenna first time in 1985. The title aperture coupled is assigned to the antenna as per its different feeding mechanism in which there is no galvanic contact between the patch antenna and feedline. The aperture is usually providing the magnetic coupling between antenna and feedline and exhibits numerous advantages. For instance, the spurious feed radiation can be reduced up to a specified level or eliminated by introducing a ground plane between the patch and feedline. Recently, the aperture coupled microstrip antenna attracted much attention of the researchers [4-6]. However, further investigations should be carried on to enhance the gain and bandwidth of this kind of antenna for the practical applications. The performance parameters of the proposed design are to be achieved by aperture couple feeding mechanism and implanting inverted
U-shaped slotted structure stepped at the corners and dimensions of the aperture slot. The resonant frequencies at different return losses throughout the band can be achieved by varying the dimensions of the slots as well as stub length of the feedline. Several antenna parameters are analyzed with the full wave analysis by using transmission line model. In recent times, a lot of research has been proposed for the advancement of the aperture coupled antennas as $\mathrm{Ku}$ band $16 \times 16$ aperture coupled array was presented by Song and Bialkowski in 1998 [7], Gao et al. proposed a broadband dualpolarized microstrip patch antenna with aperture coupling in 2003 [8] and Wong and Tung [9] demonstrated an inverted $\mathrm{U}$-shaped patch antenna for compact operation in 2003. In 2004, Rao and Johnston [10] proposed a modified aperture coupled microstrip antenna in which they employed a back cavity to block radiations from the slot. In 2005, Rao et al. [11] presented a new aperture coupled microstrip slot antenna to improve the radiation performance. Sim et al. [12] experimentally studied dual-feed dual-polarized aperture coupled patch antenna with low cross-polarization and high isolation structure in 2009. In 2012, Qin et al. [13] 
proposed an aperture coupled microstrip antenna with corrugated ground plane in which they demonstrated the gain enhancement and radiation pattern. Our proposed antenna design is simple in construction as compared to $[13,14]$, miniaturized $(7.40 \mathrm{~mm} \times 6.03 \mathrm{~mm})$ in size, low cost and increase in bandwidth $[6,12]$. Therefore, in the present work, the design considerations are presented and results are validated by numerical simulations.

\section{Design Essentials of Aperture Coupled Microstrip Patch Antenna}

Similar to electromagnetic coupling, aperture coupling is another indirect method of feeding the resonant patch. It was first proposed in 1985 for enhancement of the bandwidth of the microstrip antenna [15]. By optimizing the various parameters including the aperture dimensions, a bandwidth of nearly $15-70 \%$ has been achieved. An ACMSA (aperture coupled microstrip antenna) consists of two substrates separated by a ground plane. The top substrate contains the radiating element and the bottom substrate contains the microstrip feedline. A small aperture is cut in the ground plane to allow coupling from the open-circuited microstrip feedline to the radiating patch. The coupling aperture could be small, known as a nonresonant aperture or comparable to a half wavelength, known as a resonant aperture. The design parameters of proposed antenna are calculated by referring to the transmission line model which is detailed in two parts as Part 1 includes the standard available design parameters according to the materials opted and Part 2 describes the calculated design parameters as follows.

Part 1. Consider the following:

patch substrate material used: RT/Duroid 5880;

feed substrate material used: RT/Duroid 6006;

thickness of the patch substrate (standard): $h=$ $1.575 \mathrm{~mm}$;

thickness of the feed substrate (standard): $h=$ $0.635 \mathrm{~mm}$;

relative permittivity of patch substrate: $\varepsilon_{r P}=2.2$;

relative permittivity of feed substrate: $\varepsilon_{r f}=6.15$;

thickness of the patch: $t=0.0175 \mathrm{~mm}$;

design frequency of the proposed antenna: $11.4 \mathrm{GHz}$.

Part 2. Consider the following:

length of the patch: $L_{P}=7.962 \mathrm{~mm}$;

width of the patch: $W_{P}=6.458 \mathrm{~mm}$;

effective dielectric constant of patch substrate: $\varepsilon_{\text {reff }(P)}=1.9028$;

ground plane $\left(\right.$ length $=$ width $\left.\sim 2 \lambda_{o}\right)[16,17]: 53 \mathrm{~mm} \times$ $53 \mathrm{~mm}$;

feedline length: $L_{f}=26.5 \mathrm{~mm}$;

feed width to height ratio: $W_{f} / h_{f}=1.57$;

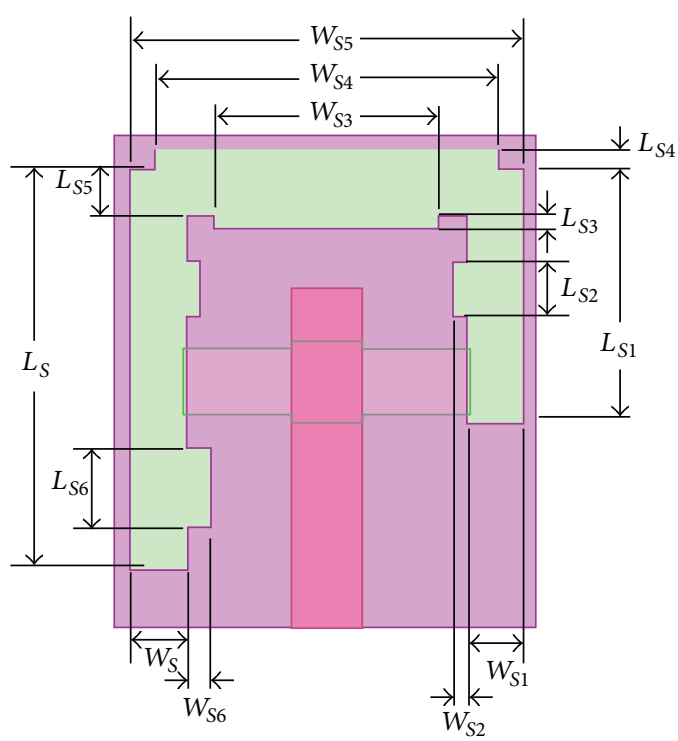

FIGURE 1: Geometry of the proposed aperture coupled patch antenna with inverted U-slot.

feedline width [18]: $W_{f}=1 \mathrm{~mm}$;

effective dielectric constant of feed substrate: $\varepsilon_{\text {reff }(f)}=$ 4.427;

theoretical characteristic impedance $[19,20]: Z_{o}=$ $48.44 \Omega$;

aperture length: $A_{L}=4.1 \mathrm{~mm}$;

Aperture width: $A_{W}=1 \mathrm{~mm}$;

Stub length: $L_{S}=1.6 \mathrm{~mm}$.

\section{Proposed Aperture Coupled Patch Antenna Configuration}

The architecture of the aperture coupled microstrip patch antenna embedded with inverted U-slot and small tuning stubs is represented in Figure 1. The dimensions of the aperture slot and feedline are clearly represented in Figure 2. The dimensions of the radiating structures, aperture slot, and microstrip feedline are chosen according to [2]. The dimensions of inverted U-slot with small tuning stubs on it are adjusted to radiate apparently around the resonant frequency and their position is selected so that the radiating structure must be capable of producing wider bandwidth and proper impedance matching.

Moreover, the dimensions of the aperture slot and the size of the feedline stub are responsible for the proper impedance matching between the microstrip feedline and the radiating patch. It is important to discuss here that if the coupling between the feedline and radiating structure is not achieved, most of the fed signals will be reflected which results in the performance deterioration.

The length and width of the radiating patch are finite, and consequently the radiated fields at the radiating edges of the antenna experience fringing. Fringing affects the dimensions 
TABLE 1: Geometrical parameters of analyzed antenna (all dimensions in mm).

\begin{tabular}{|c|c|c|c|c|c|c|}
\hline Antenna parameters & Design 1 & Design 2 & Design 3 & Design 4 & Design 5 & Design 6 \\
\hline$L$ & 7.96 & 7.96 & 7.96 & 7.40 & 7.40 & 7.40 \\
\hline$W$ & 6.45 & 6.45 & 6.45 & 6.03 & 6.03 & 6.03 \\
\hline$L_{S}$ & NA & 6.0 & 6.0 & 6.0 & 6.0 & 6.0 \\
\hline$W_{S}$ & NA & 0.8 & 0.8 & 0.8 & 0.8 & 0.8 \\
\hline$L_{S 1}$ & NA & NA & 3.8 & NA & 3.8 & 3.8 \\
\hline$W_{S 1}$ & NA & NA & 0.8 & NA & 0.8 & 0.8 \\
\hline$L_{S 2}$ & NA & NA & NA & NA & NA & 0.8 \\
\hline$W_{S 2}$ & NA & NA & NA & NA & NA & 0.2 \\
\hline$L_{S 3}$ & NA & NA & NA & NA & NA & 0.2 \\
\hline$W_{S 3}$ & NA & NA & NA & NA & NA & 3.2 \\
\hline$L_{S 4}$ & NA & NA & NA & 0.3 & 0.3 & 0.3 \\
\hline$W_{S 4}$ & NA & NA & NA & 4.9 & 4.9 & 4.9 \\
\hline$L_{S 5}$ & NA & NA & NA & 0.7 & 0.7 & 0.7 \\
\hline$W_{S 5}$ & NA & NA & NA & 5.6 & 5.6 & 5.6 \\
\hline$L_{S 6}$ & NA & NA & NA & NA & NA & 1.2 \\
\hline$W_{S 6}$ & NA & NA & NA & NA & NA & 0.35 \\
\hline$A_{W}$ & 1.0 & 1.0 & 1.0 & 1.0 & 1.0 & 1.0 \\
\hline$A_{L}$ & 4.1 & 4.1 & 4.1 & 4.1 & 4.1 & 4.1 \\
\hline$S_{W}$ & 1.2 & 1.2 & 1.2 & 1.2 & 1.2 & 1.2 \\
\hline$S_{L}$ & 1.0 & 1.0 & 1.0 & 1.0 & 1.0 & 1.0 \\
\hline
\end{tabular}

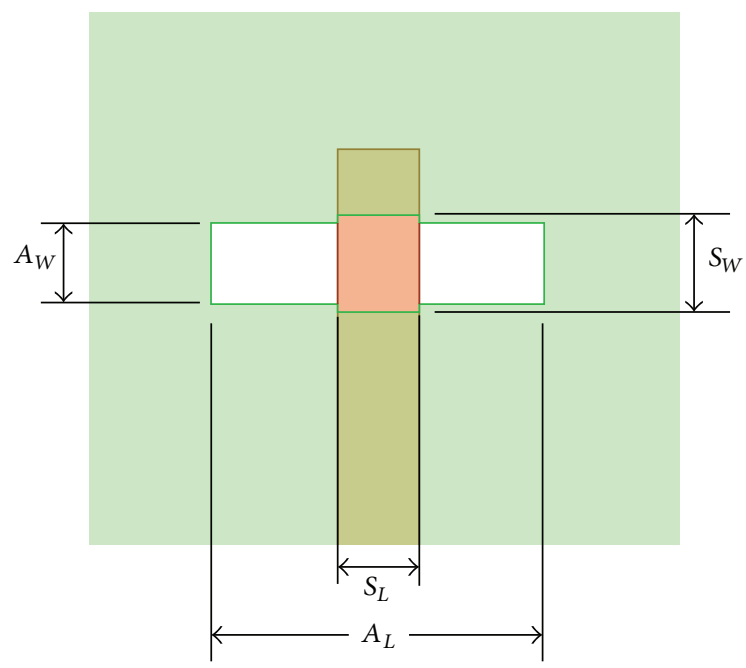

FIGURE 2: Dimensions of the aperture slot and feedline.

of patch height and dielectric constant of substrate and hence the resonant frequency. The constructional detail of the proposed antenna is shown in Figure 1; dimensions of the patch, slots, and small stubs are mentioned in Table 1. All the design parameters of the proposed antenna tabulated in Table 1 are calculated as per the transmission line model and iterative trials. As listed in Table 2, first of all, design 1 is analyzed and necessary modifications have been done in a progressive manner to achieve the final optimum designs that is design 6.

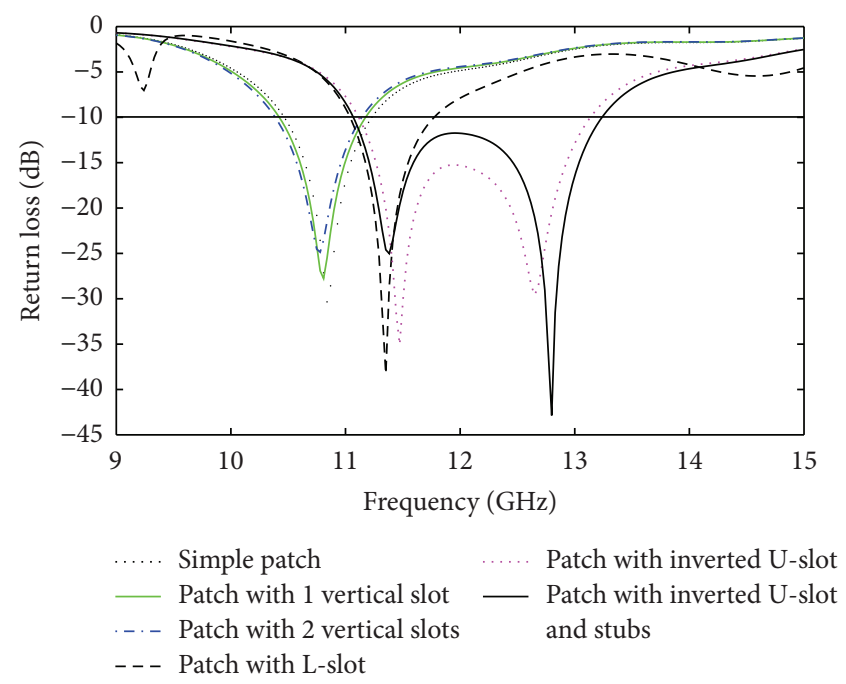

FIGURE 3: Return loss plot of all the designs in which solid black line plot represents the return loss of proposed antenna.

\section{Discussion of Results}

Our attention is focused on the discussion and presentation of calculated and measured results for the return loss, VSWR, gain, and radiation pattern of the proposed antenna design in this section. The frequency range of $10 \mathrm{GHz}$ to $14 \mathrm{GHz}$ is utilized for the analysis purpose of the proposed design. Figure 3 is representing the return loss plots as per design 1 to design 6 mentioned in Table 1. We observed that simple 


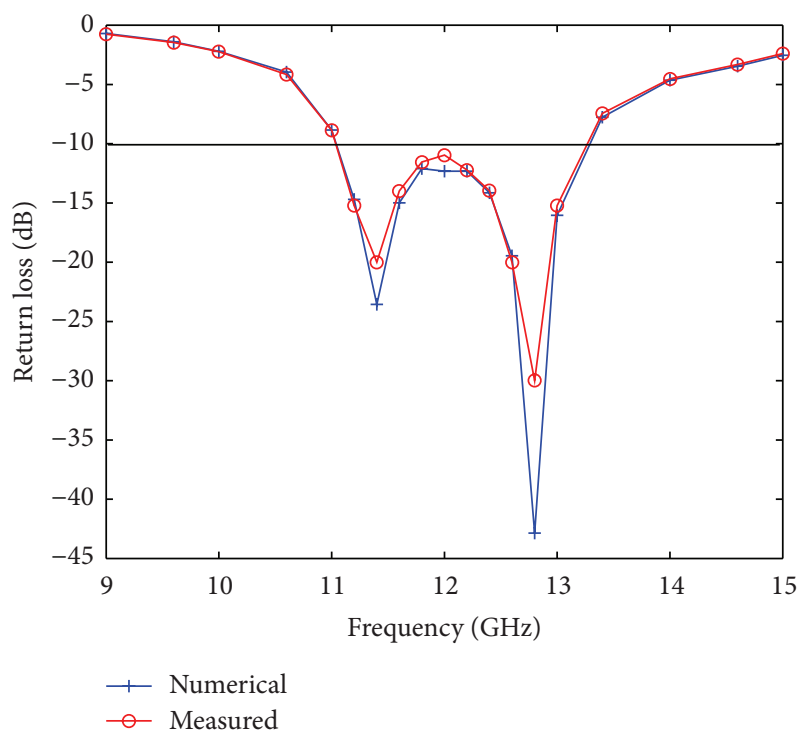

Figure 4: Return loss versus frequency plot of calculated and measured results of proposed antenna.

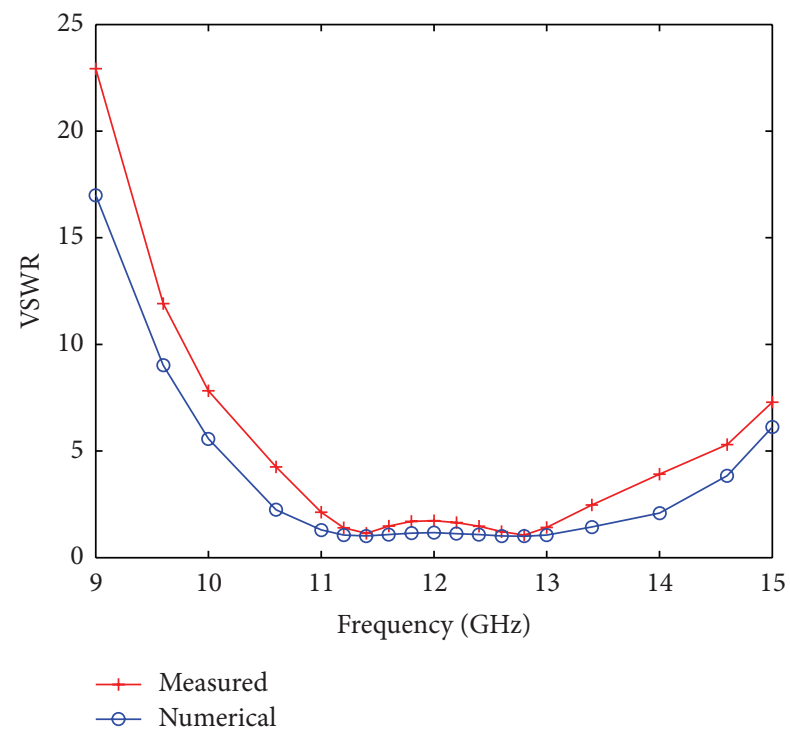

FIGURE 5: VSWR versus frequency plot of calculated and measured results of proposed antenna.

aperture coupled patch antenna (black dotted plot) exhibits $-30 \mathrm{~dB}$ return loss at $10.84 \mathrm{GHz}$ resonant frequency and $790 \mathrm{MHz}(10.43 \mathrm{GHz}$ to $11.22 \mathrm{GHz})$ absolute bandwidth.

Further improvements have been achieved in the design after applying different patterns and positions of slots as represented in Figure 1. At the very first step, design 1 of Table 1 is modified to design 2 by employing one vertical slot of length $L_{S}=6 \mathrm{~mm}$ and $W_{S}=0.8 \mathrm{~mm}$ on the radiating patch and we observed slight decrease in resonant frequency from $10.84 \mathrm{GHz}$ to $10.8 \mathrm{GHz}$ and bandwidth increases by $10 \mathrm{MHz}$ and return loss is $-28 \mathrm{~dB}$ shown as green line

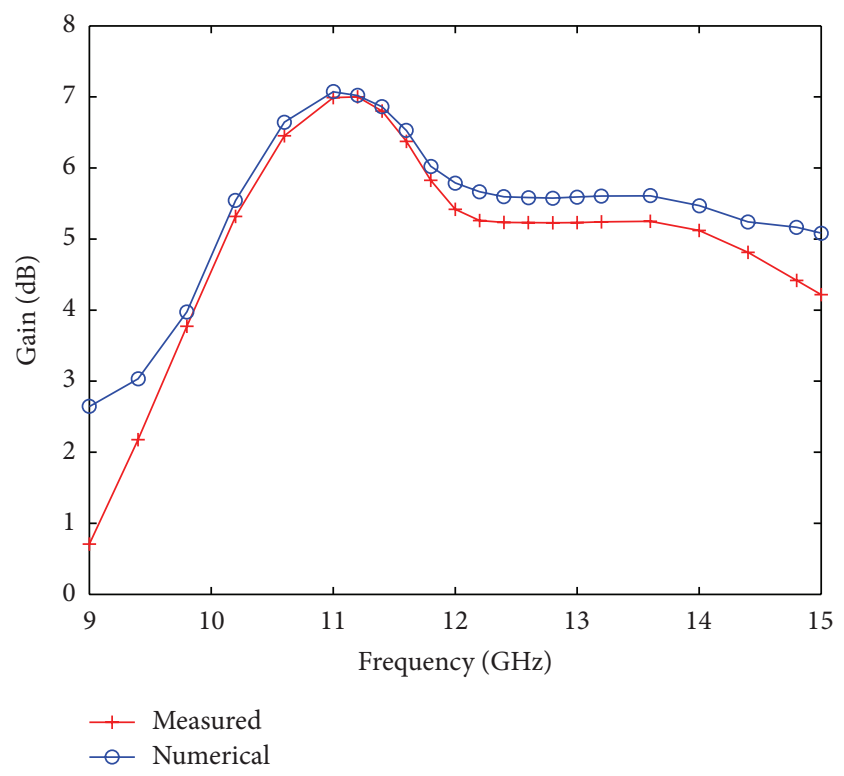

FIGURE 6: Gain versus frequency plot of calculated and measured results of proposed antenna.

TABLE 2: Description of antenna designs mentioned in Table 1.

\begin{tabular}{ll}
\hline Antenna designs & Description of designs \\
\hline Design 1 & $\begin{array}{l}\text { Simple aperture coupled patch antenna } \\
\text { Aperture coupled patch with one vertical } \\
\text { slot }\end{array}$ \\
Design 2 & $\begin{array}{l}\text { Aperture coupled patch with two vertical } \\
\text { slots }\end{array}$ \\
Design 3 & Aperture coupled patch with L-slot \\
Design 4 & $\begin{array}{l}\text { Aperture coupled patch with inverted U-slot } \\
\text { Aperture coupled inverted U-slot patch with } \\
\text { Design 5 }\end{array}$ \\
Design 6 & \\
\hline
\end{tabular}

plot. Antenna design 2 is modified with antenna design 3 by implanting another slot on the radiating patch having dimensions $L_{S 1}=3.8 \mathrm{~mm}$ and $W_{S 1}=0.8 \mathrm{~mm}$ and observed that the resonant frequency decreases from $10.8 \mathrm{GHz}$ to $10.79 \mathrm{GHz}$ and bandwidth decreases to $740 \mathrm{MHz}$ and return loss decreases to $-25 \mathrm{~dB}$ shown in Figure 5 and denoted as dash-dot line structure. The reason for this degradation is that the radiation from two vertical slots on either side of the patch is not coupled mutually because these slots are departed by the conducting patch; therefore, it decreases in bandwidth. By taking into consideration this degradation, the antenna is further improved as design 4 in which a squared truncated inverted L-slot is implanted on the patch having dimensions listed in Table 1 . The result of design 4 is shown in Figure 3 and represented with the dashed line; it exhibits a drastic change in return loss which is $-38 \mathrm{~dB}$ at resonant frequency $11.38 \mathrm{GHz}$ and the bandwidth remains unaltered that is $800 \mathrm{MHz}$. With these modifications in the design, we have achieved the appropriate return loss and VSWR, but the goal of bandwidth enhancement has not been achieved 

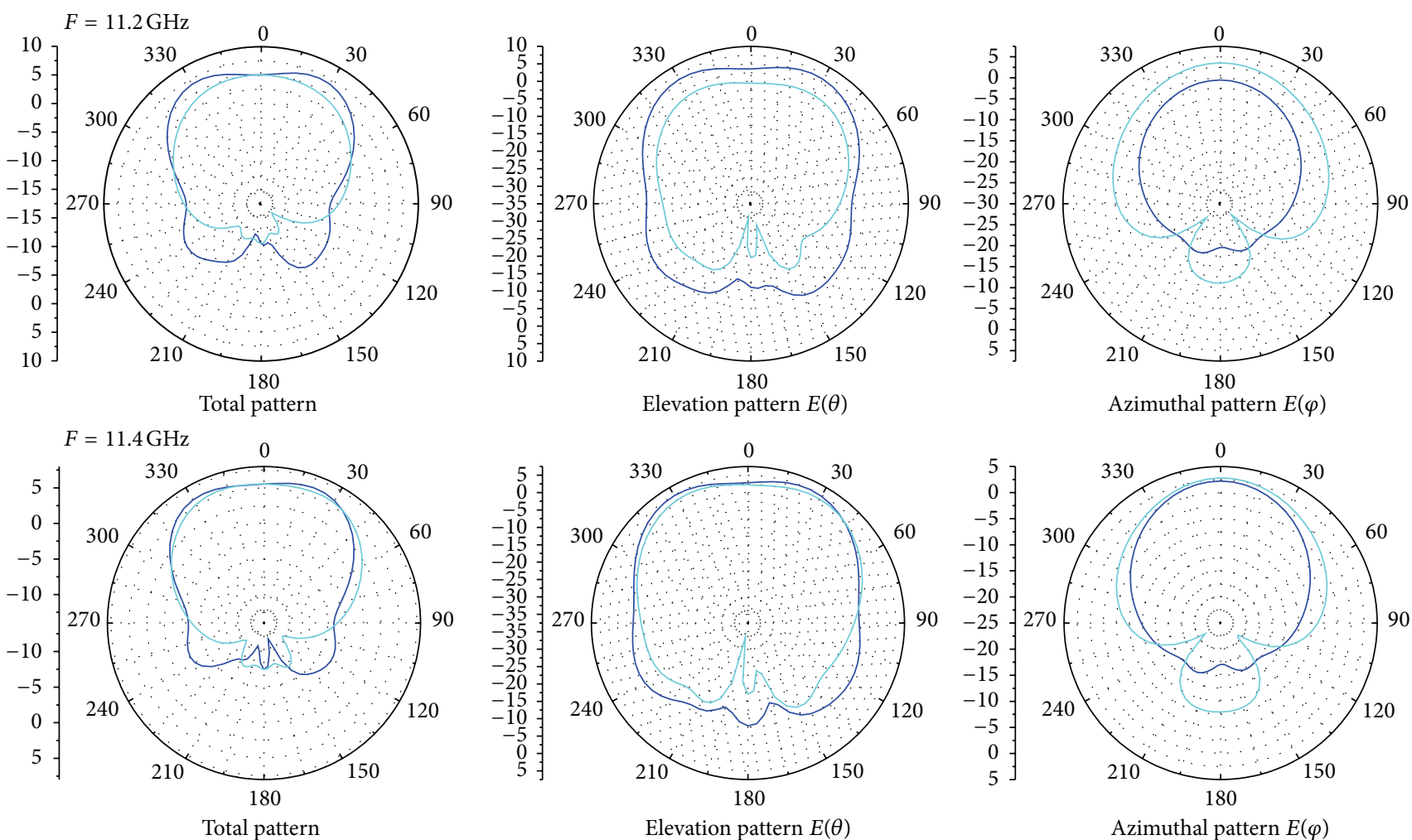

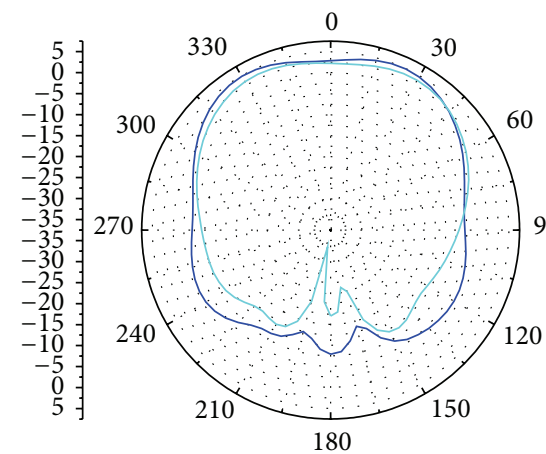

Elevation pattern $E(\theta)$

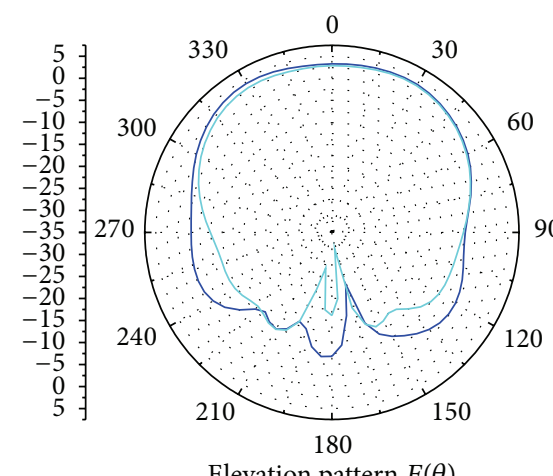

Elevation pattern $E(\theta)$

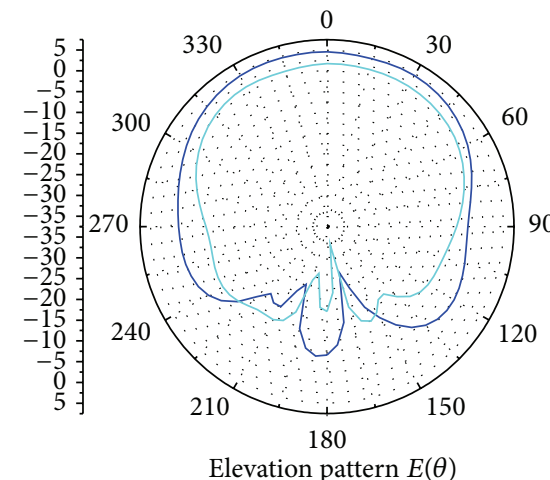

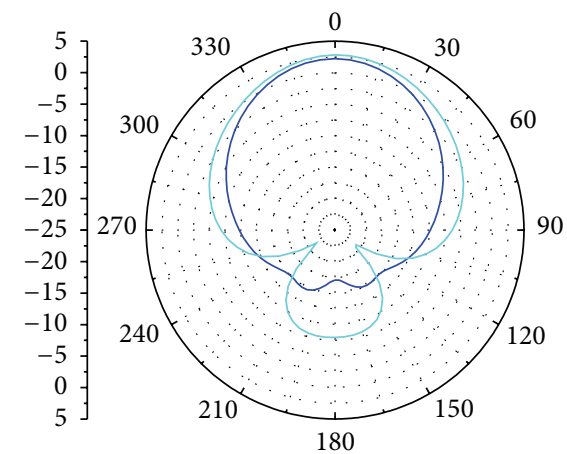

Azimuthal pattern $E(\varphi)$

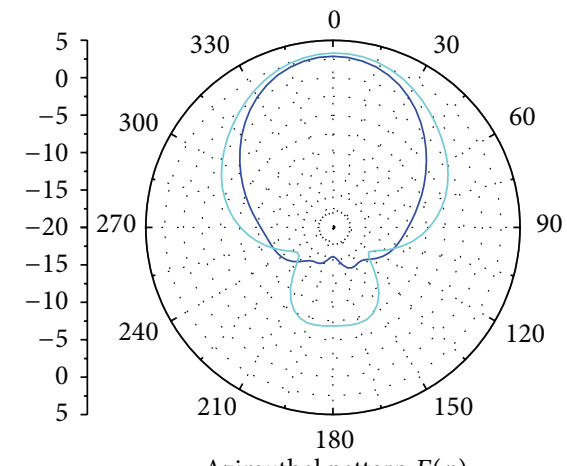

Azimuthal pattern $E(\varphi)$

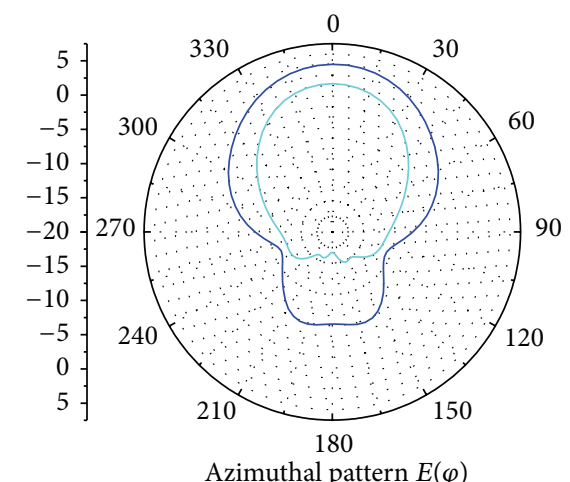

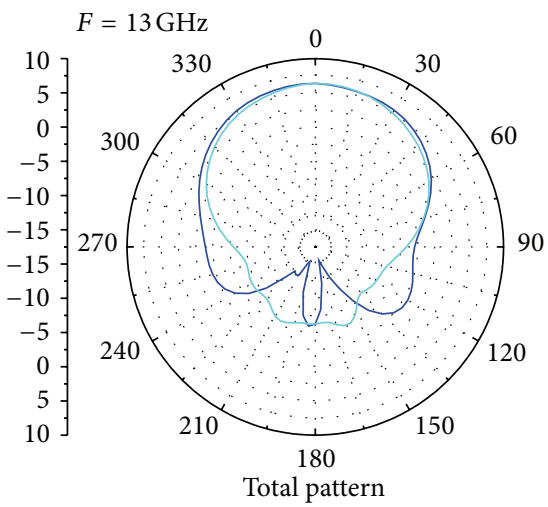

FIGURE 7: 2D radiation patterns of aperture coupled microstrip patch antenna by using inverted U-slot. 
TABLE 3: Return loss, gain, and bandwidth of all the design analysed in this work.

\begin{tabular}{lcccc}
\hline Antenna performance & Operating frequency & Return loss & Gain & Bandwidth \\
\hline Design 1 & $10.84 \mathrm{GHz}$ & $-30 \mathrm{~dB}$ & $7 \mathrm{~dB}$ & $790 \mathrm{MHz}$ \\
Design 2 & $10.80 \mathrm{GHz}$ & $-28 \mathrm{~dB}$ & $700 \mathrm{MHz}$ \\
Design 3 & $10.79 \mathrm{GHz}$ & $-25 \mathrm{~dB}$ & $7.5 \mathrm{~dB}$ & $740 \mathrm{MHz}$ \\
Design 4 & $11.38 \mathrm{GHz}$ & $-38 \mathrm{~dB}$ & $6.95 \mathrm{~dB}$ & $800 \mathrm{MHz}$ \\
Design 5 & $11.45 \mathrm{GHz}$ & $-35 \mathrm{~dB}$ & $6.87 \mathrm{~dB}$ & $2000 \mathrm{MHz}$ \\
Design 6 & $11.45 \mathrm{GHz}$ & $-43 \mathrm{~dB}$ & $6.97 \mathrm{~dB}$ & $2170 \mathrm{MHz}$ \\
\hline
\end{tabular}

so far. No doubt that the antennas having bandwidth more than $500 \mathrm{MHz}$ can be categorized as wideband antenna, but still we will try to reach up to the considerable amount of bandwidth by improving our design. Design 5 with reference to Table 1 is another enhancement which we have reached by implanting an inverted U-slot having dimensions as per Table 1 . It is found that the bandwidth has increased with this design as $2000 \mathrm{MHz}$ and the return loss is below the threshold value in the frequency range of $11.11 \mathrm{GHz}$ to $13.13 \mathrm{GHz}$. Utmost value of return loss is attained, $-35 \mathrm{~dB}$ at $11.45 \mathrm{GHz}$ frequency and $-30 \mathrm{~dB}$ at $12.65 \mathrm{GHz}$ frequency. Furthermore, some small stub slots are added in the inverted U-slot structure and dimensions of these slots are detailed under design 6 of Table 1. In this absolute design, we have attained $2170 \mathrm{MHz}$ bandwidth $(11.08 \mathrm{GHz}-13.25 \mathrm{GHz})$ with the maximum return loss of $-43 \mathrm{~dB}$ as undoubtedly represented in Figure 3 with solid black line plot which are the tremendous values of bandwidth and return loss so far. Further, the calculated and measured results of return loss and VSWR are presented in Figures 4 and 5, respectively. The incident power used for these measurements was $10 \mathrm{~mW}$ and it is observed from the measured return loss and VSWR that $92 \%$ to $99.2 \%$.

Power is Accepted by the proposed antenna in the frequency range of $11 \mathrm{GHz}-13.2 \mathrm{GHz}$. A radiation efficiency of $91 \%$ to $97 \%$ is achieved throughout the specified frequency range. Finally, it is observed from Figures 4 and 5 that a good agreement has been achieved between the calculated and measured return loss and VSWR values.

Figure 6 represents gain versus frequency plot through which it is undoubtedly observed that the proposed antenna design exhibits acceptable gain $(5.5 \mathrm{~dB}$ to $6.97 \mathrm{~dB})$ within the frequency range of $11 \mathrm{GHz}-13.2 \mathrm{GHz}$.

A good agreement has also been achieved between the calculated and measured value of gain throughout the required frequency range. All the important parameters which we have discussed in the paper are tabulated in Table 3 so that they can easily be recognized and compared with each other. The VSWR values for all the designs have not been shown because all of these antenna designs exhibited a good value of VSWR which should range between 1 and 2 .

It is observed from Table 3 that with antenna design 6, a good agreement amongst all the important parameters has been achieved.

The measured $2 \mathrm{D}$ radiation patterns at different resonant frequencies are presented in Figure 7 . The radiation characteristics are also studied in azimuthal plane ( $x-y$ planes) and elevation plane ( $y$ - $z$ planes $)$ and it is observed that the proposed antenna is radiating more in the theta ( $y-z$ planes) direction and less in the phi ( $x-y$ planes) direction. Normally, the radiation characteristics are determined in the far field region as a function of coordinates and it can also be classified in terms of power pattern or field pattern. Moreover, from the total patterns of all resonant frequencies, it is clear that major lobe is stronger than the back lobe and side lobes and it is analysed that this proposed antenna is radiating normally to the antenna surface.

\section{Conclusions}

The design of inverted U-slot aperture coupled wideband microstrip patch antenna is analyzed and discussed in this work. The performance parameters of the antenna as detailed in Table 3 are achieved in a good agreement after applying slight modifications to the base design to reach up to the final optimum wideband design. Moreover, the design resulted in a smaller size antenna with a wide bandwidth operation. A good agreement between calculated and measured return loss, VSWR, and gain is achieved. All the results of the proposed design are presented and discussed and it is concluded that this antenna will give the satisfactory performance in the band of operating frequencies $(11 \mathrm{GHz}-13.5 \mathrm{GHz})$.

\section{Conflict of Interests}

The authors declare that there is no conflict of interests regarding the publication of this paper.

\section{References}

[1] I. J. Bahl and P. Bhartia, Microstrip Antennas, Artech House, Boston, Mass, USA, 1980.

[2] C. A. Balanis, Antenna Theory, Analysis and Design, John Wiley \& Sons, New York, NY, USA, 1997.

[3] D. M. Pozar, "Microstrip antenna aperture coupled to a microstripline," Electronics Letters, vol. 21, no. 2, pp. 49-50, 1985.

[4] S. K. Padhi, N. C. Karmakar, C. L. Law, and S. Aditya, "A dual polarized aperture coupled circular patch antenna using a c-shaped coupling slot," IEEE Transactions on Antennas and Propagation, vol. 51, no. 12, pp. 3295-3298, 2003.

[5] C. H. Tsao, Y. M. Hwang, F. Kilburg, and F. Dietrich, "Aperture coupled patch antennas with widebandwidth and dual polarization capabilities," in Proceedings of the IEEE Antennas and Propagation Symposium Digest, pp. 936-939, 1988. 
[6] W. J. Tseng and S. J. Chung, "Analysis and application of a twoport aperture-coupled microstrip antenna," IEEE Transactions on Microwave Theory and Techniques, vol. 46, no. 5, pp. 530535,1998 .

[7] H. J. Song and M. E. Bialkowski, "Ku-Band $16 \times 16$ planar array with aperture-coupled microstrip-patch elements," IEEE Antennas and Propagation Magazine, vol. 40, no. 5, pp. 25-29, 1998.

[8] S. Gao, L. W. Li, M. S. Leong, and T. S. Yeo, "A broad-band dualpolarized microstrip patch antenna with aperture coupling," IEEE Transactions on Antennas and Propagation, vol. 51, no. 4, pp. 898-900, 2003.

[9] K. L. Wong and H. C. Tung, "An inverted U-shaped patch antenna for compact operation," IEEE Transactions on Antennas and Propagation, vol. 51, no. 7, pp. 1647-1648, 2003.

[10] Q. Rao and R. H. Johnston, "Modified aperture coupled microstrip antenna," IEEE Transactions on Antennas and Propagation, vol. 52, no. 12, pp. 3397-3401, 2004.

[11] Q. Rao, T. A. Denidni, and R. H. Johnston, "A new aperture coupled microstrip slot antenna," IEEE Transactions on Antennas and Propagation, vol. 53, no. 9, pp. 2818-2826, 2005.

[12] C. Y. Sim, C. C. Chang, and J. S. Row, "Dual-feed dual-polarized patch antenna with low cross polarization and high isolation," IEEE Transactions on Antennas and Propagation, vol. 57, no. 10, pp. 3321-3324, 2009.

[13] K. Qin, M. Li, H. Xia, and J. Wang, "A new compact aperturecoupled microstrip antenna with corrugated ground plane," IEEE Antennas and Wireless Propagation Letters, vol. 11, pp. 807810, 2012.

[14] M. M. Honari, A. Abdipour, and G. Moradi, "Bandwidth and gain enhancement of an aperture antenna with modified ring patch," IEEE Antennas and Wireless Propagation Letters, vol. 10, pp. 1413-1416, 2011.

[15] M. Ali, A. Kachouri, and M. Samet, "Novel method for planar microstrip antenna matching impedance," Journal of Telecommunications, vol. 2, pp. 131-138, 2010.

[16] R. Garg, P. Bhartia, I. Bahl, and A. Ittipibon, Microstrip Antenna Design Handbook, Artech House, Boston, Mass, USA, 2001.

[17] E. Lier and K. R. Jakobsen, "Rectangular microstrip patch antenna with infinite and finite ground plane dimensions," IEEE Transactions on Antennas and Propagation, vol. 31, no. 6, pp. 978-984, 1983.

[18] H. A. Wheeler, "Transmission line properties of parallel strips separated by a dielectric sheet," IEEE Transactions on Microwave Theory and Techniques, vol. 13, pp. 172-185, 1965.

[19] E. O. Hammerstadt, "Equations for microstrip circuit design," in Proceedings of the 5th European Microwave Conference, pp. 268-272, September 1975.

[20] I. J. Bahl and R. Garg, "Simple and accurate formulas for microstrip with finite strip thickness," Proceedings of the IEEE, vol. 65, no. 11, pp. 1611-1612, 1977. 

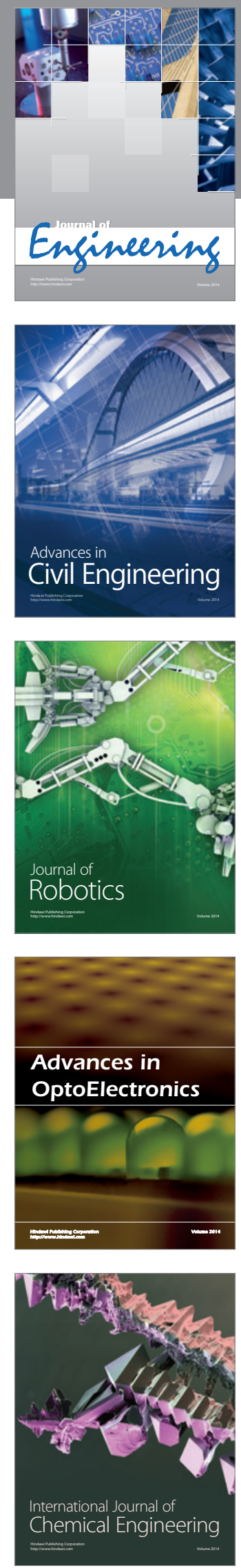

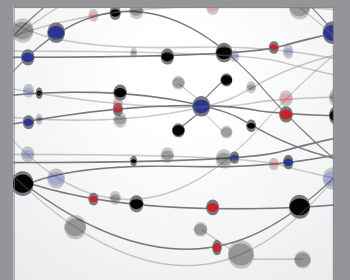

The Scientific World Journal
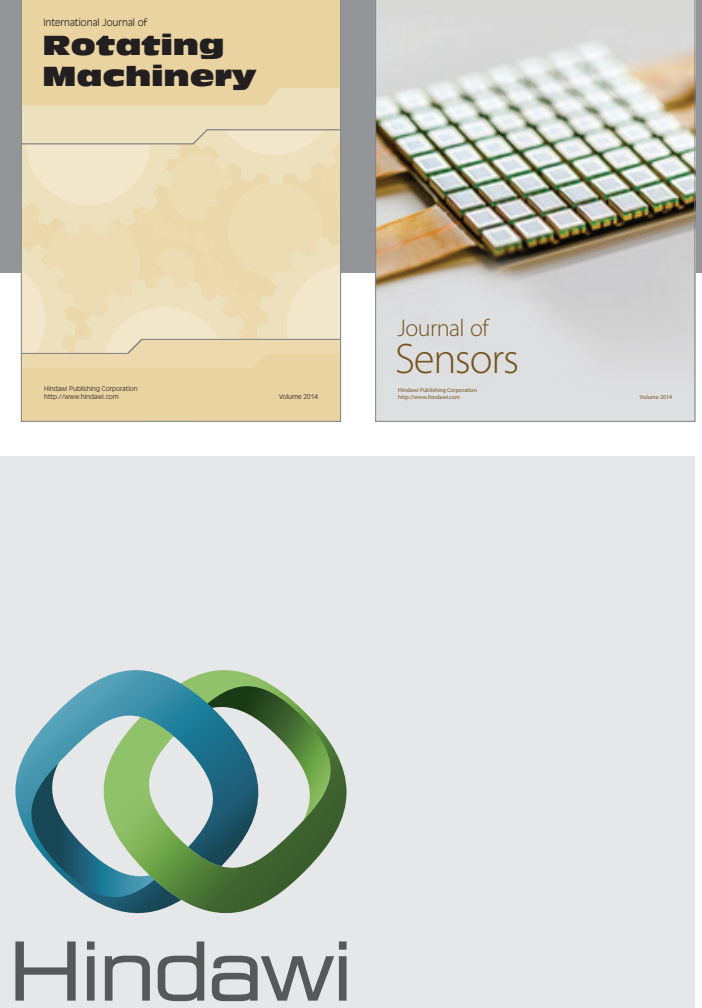

Submit your manuscripts at http://www.hindawi.com
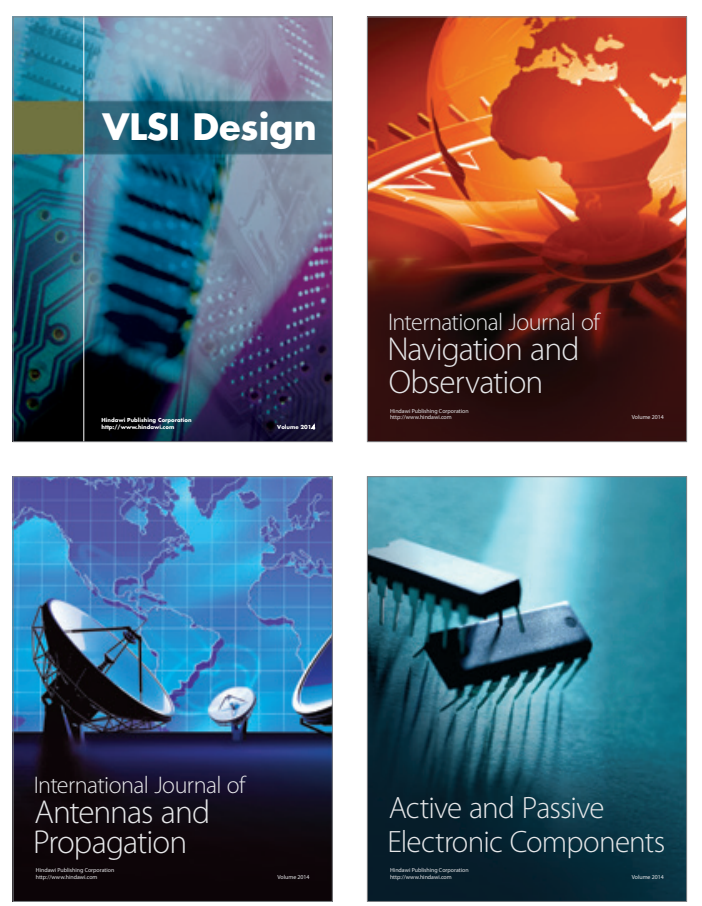
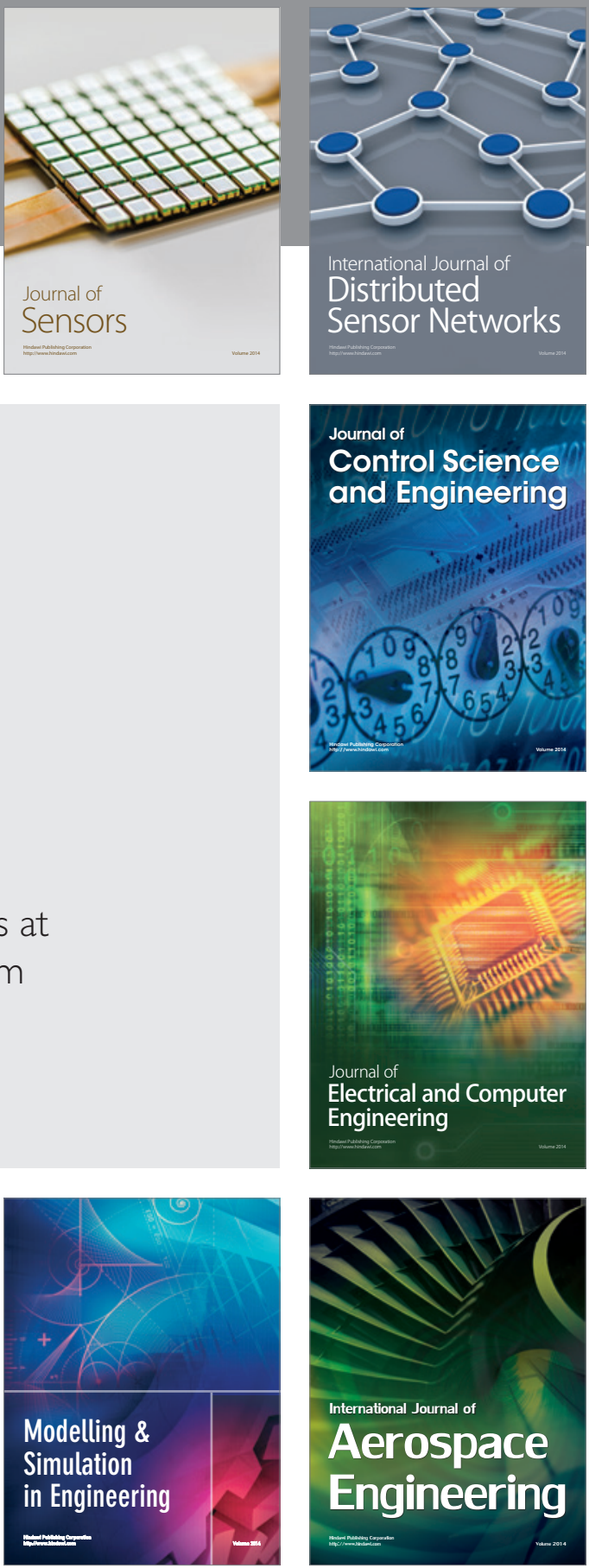

Journal of

Control Science

and Engineering
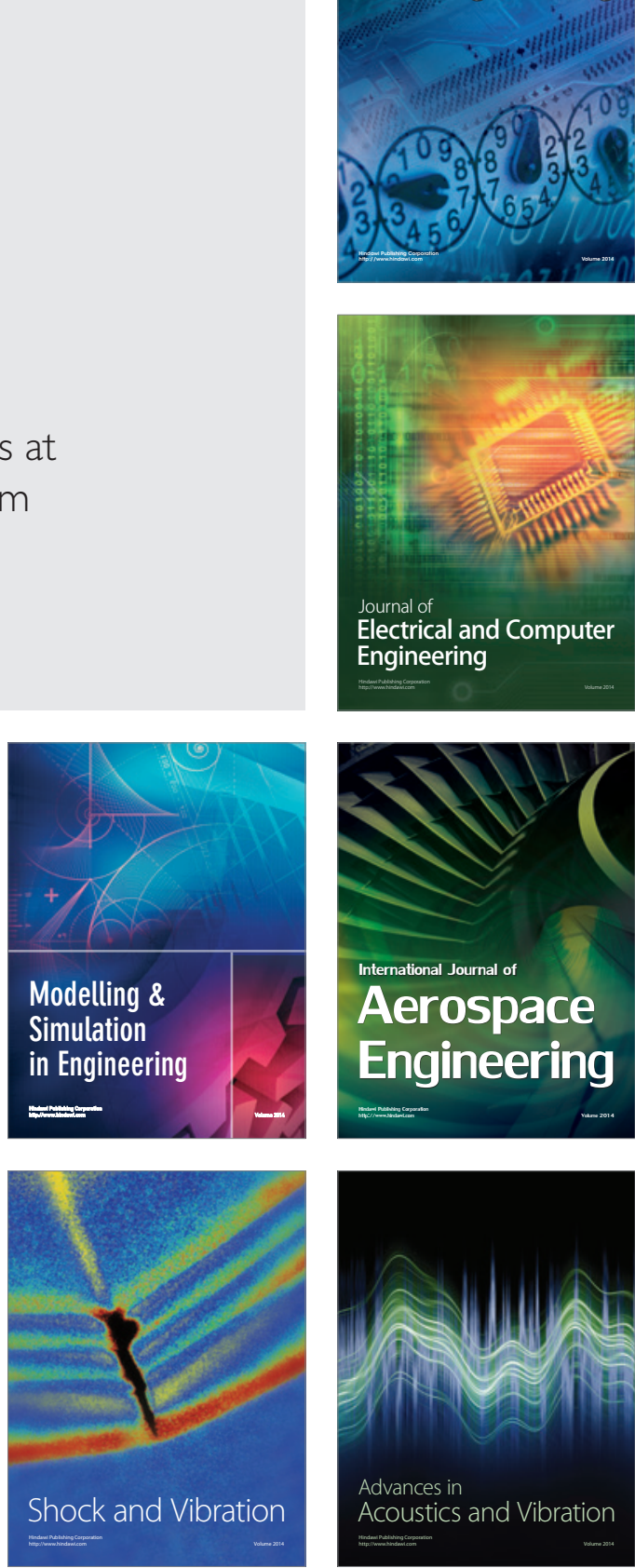